\title{
Towards food supply chain resilience to environmental shocks
}

\author{
Kyle Frankel Davis $\oplus^{1,2,3 凶}$, Shauna Downs ${ }^{4}$ and Jessica A. Gephart $\oplus^{5}$
}

\begin{abstract}
Environmental variability and shock events can be propagated or attenuated along food supply chains by various economic, political and infrastructural factors. Understanding these processes is central to reducing risks associated with periodic food shortages, price spikes and reductions in food quality. Here we perform a scoping review of the literature to examine entry points for environmental variability along the food supply chain, the evidence of propagation or attenuation of this variability, and the food items and types of shock that have been studied. We find that research on food supply shocks has primarily focused on maize, rice and wheat, on agricultural production and on extreme rainfall and temperatures-indicating the need to expand research into the full food basket, diverse sources of environmental variability and the links connecting food production to consumption and nutrition. Insights from this new knowledge can inform key responses-at the level of an individual (for example, substituting foods), a company (for example, switching sources) or a government (for example, strategic reserves)for coping with disruptions.
\end{abstract}

ood production, storage, processing, distribution, retail and consumption are all exposed to wide-ranging forms of environmental change, including slow-moving changes in average conditions (for example, climate, nutrient and water cycling), smaller-magnitude variations around those means and larger, anomalous disruptions ${ }^{1,2}$. Environmental variability and disruptions are manifested not only as floods, droughts and extreme heat (that is, climate variability) but also as natural hazards, pests, disease, algal blooms, coral bleaching and aflatoxins ${ }^{3-5}$.

Environmental variability includes fluctuations within the historical range but increasingly consists of extreme-and at times unprecedented-events driven by climate change and other forms of human-environmental change. While expected changes in climatic and environmental conditions over the coming decades will certainly have important implications for future food security, nutrition, and human and planetary health ${ }^{1,2,4,6,7}$, environmental variability and extreme events are already leading to harvest losses and distribution disruptions each year ${ }^{8}$. In many cases, these short-term impacts (that is, those occurring within the span of a production/ growing season) have been shown to be stronger than those caused by slow-moving changes in climate and the environment ${ }^{7}$. Such developments point to a growing need to protect the stability of not only food production but also other steps in food supply chains in the face of rising environmental variability and risk 9 .

Environmental variability can affect food supply chains at local to global scales. In regions with limited global market access and where food production and consumption are tightly coupled (that is, short supply chains common in subsistence-based food systems), environmental variability can more readily translate into local shortages of specific foods ${ }^{10}$, creating food insecurity depending on available substitutes, the impacts on livelihoods ${ }^{11}$, and how household diets and nutrient intake are modified ${ }^{12}$. Increasingly, the impacts of environmental variability are not limited to local producers but spread through longer supply chains. A prominent example was seen in 2008, when a drought in key grain-producing regions, combined with rising biofuel demand, high oil prices, decreasing grain stocks and the depreciation of the US dollar, led to a spike in global grain prices ${ }^{13}$. That set off a series of rice export bans, furthering shortages and ultimately driving more than 130 million people into poverty and an additional 75 million people into malnourishment ${ }^{13}$. Although only partially an environmental shock, this global-scale disruption illuminated the potential for shocks to cascade through the food trade network and to impact geographically distant places and people.

As food supply chains grow increasingly globalized, it is important to understand the potential novel risks of how environmental variability is propagated or attenuated within food systems. Ongoing globalization and the rise of multinational food corporations have enhanced the efficiency and complexity with which producers and consumers are linked. Research is only beginning to understand how these dynamics influence the propagation of the effects of environmental variability through global and local food supply chains, how large-scale events (for example, blockades, recessions and pandemics $)^{14-16}$ may compound these effects, and what they ultimately mean for the stability and affordability of nutritious diets. Identifying the key processes and actors in food supply chains-and understanding their interactions with, and exposure to, environmental variability and the economy-is central to reducing food and nutrition security risks associated with periodic food shortages and to improving resilience within food systems.

Here we perform a scoping review (Extended data Fig. 1) to synthesize existing knowledge on the impacts of environmental variability on food supply chains and the transfer of such impacts along local and global food supply chains. We first highlight the entry points for environmental variability along each step in the supply chain, drawing on examples from the scoping review. Then, we present the quantitative review results related to which food items, supply chain steps and types of environmental variability have been the focus of research to date. Finally, we summarize the qualitative review results on the response option space for actors along the supply chain.

${ }^{1}$ Department of Geography and Spatial Sciences, University of Delaware, Newark, DE, USA. ${ }^{2}$ Department of Plant and Soil Sciences, University of Delaware, Newark, DE, USA. ${ }^{3}$ Data Science Institute, Columbia University, New York, NY, USA. ${ }^{4}$ Department of Urban-Global Public Health, Rutgers School of Public Health, Piscataway, NJ, USA. ${ }^{5}$ Department of Environmental Science, American University, Washington DC, USA. $\varpi_{e}$-mail: kfdavis@udel.edu 


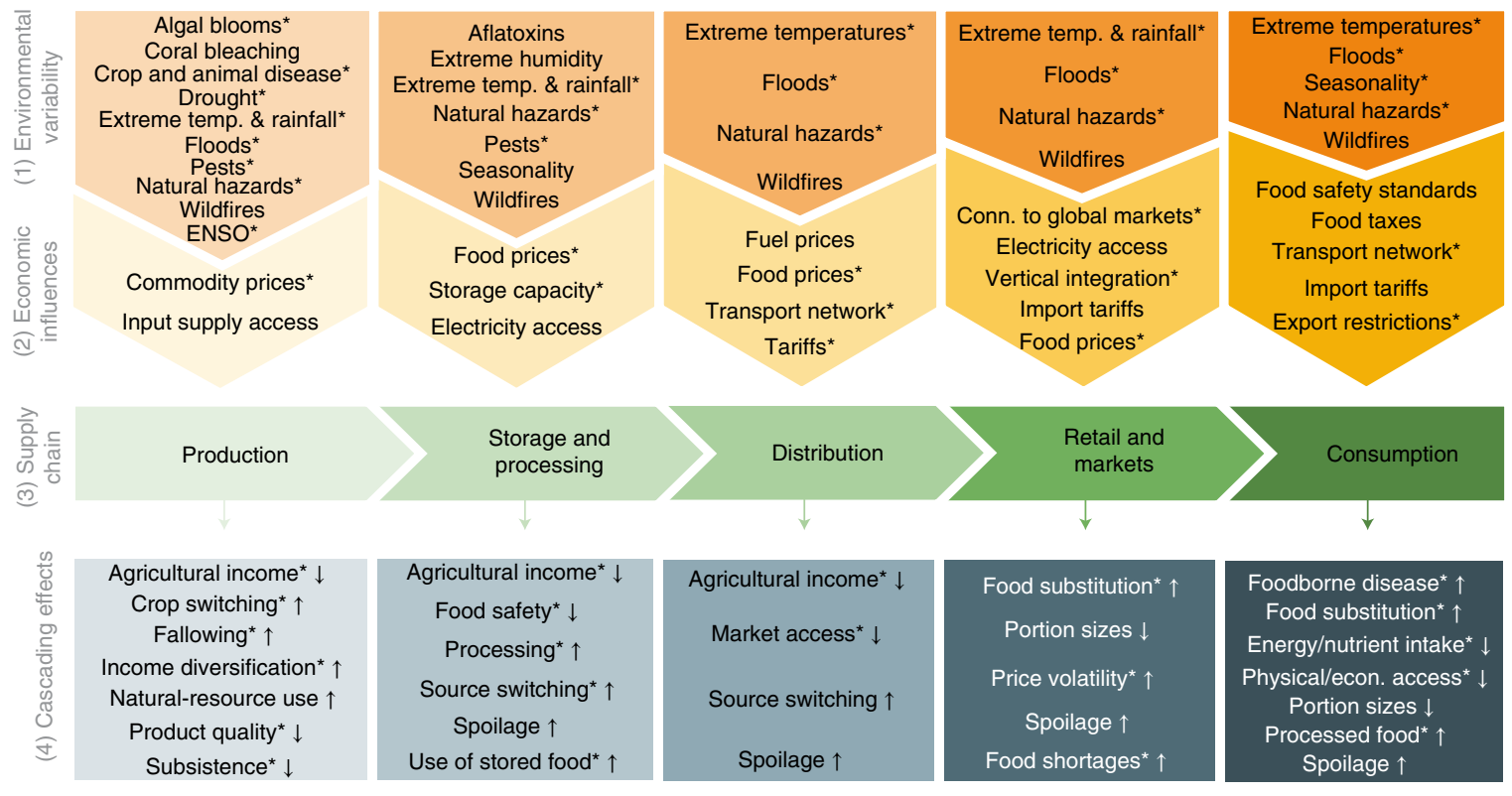

Fig. 1 | Entry points for environmental variability in food supply chains. 1) Environmental variability can enter at each step of the food supply chain. 2) Economic conditions and infrastructure quality can dampen or enhance these environmental factors. A variety of geopolitical and other economic factors influencing the interactions of environmental variability and food supply chains are also discussed in the text. 3) The impacts of this variability on food quantity and quality can also be passed between steps in the food supply chain. 4) The cascading effects represent the main outcomes that could occur without intervention from supply chain actors, and the direction of the arrow next to each effect indicates whether there would be an expected increase or decrease. Depending on the specific context, only certain cascading effects may emerge in response to environmental variability. The asterisks indicate a type of environmental variability, economic influence or cascading effect that was identified within the scoping review. Temp., temperature; conn.,

connectivity; econ., economic.

On the basis of our findings, we contend that a new wave of food systems research focused on the full food basket, diverse forms of environmental variability and local-to-global interactions across the supply chain is required to understand the diverse impacts of environmental variability on the spectrum of food systems. This new knowledge can inform a range of policy options and business decisions across the supply chain that provide flexibility in responding to variability in food supplies and that enhance the resilience and adaptability of food systems to known and novel shocks.

\section{Results}

Entry points for environmental variability. Environmental variability can affect the quantity, quality and timing of food as it travels through the supply chain (Fig. 1). Most entry points for environmental variability to impact food supply chains occur at production. Exposure to variability and shocks is particularly pronounced for rainfed agriculture and smallholders (that is, households with $<5$ ha), who account for the majority of the world's food production $\left(57 \%\right.$ (ref. $\left.{ }^{17}\right)$ and $55 \%\left(\right.$ ref. $\left.{ }^{18}\right)$, respectively) and rely largely on locally available natural resources. A large body of literature documents the impacts of floods, droughts, natural disasters and other extreme events on food production ${ }^{19-21}$. In some instances (for example, disease and pests), individual food items may be impacted, while other phenomena (for example, large-scale drought and algal blooms) may induce declines across entire portions or regions of the food production basket. Environmental variability also presents challenges related to the quality and safety of food items, possibly leading to changes in the nutrient content of some species as well as increased food safety risks. Increasing variations in rainfall have been linked to greater variability in the protein content of wheat ${ }^{22}$ while higher temperatures have been associated with changes in the fatty acid content of some fish ${ }^{4,23}$ and declining milk quality in dairy $\operatorname{cows}^{24}$. Temperature, humidity and precipitation variability, along with increased pests, are associated with increased aflatoxin levels during production, while algal blooms can produce toxins that enhance the risk of shellfish poisoning ${ }^{25,26}$. Environmental variability also affects the transmission of animal diseases (which can necessitate mass animal culling or fishery closures), foodborne illness and zoonosis (that is, animal-to-human transmission).

Specifically concerning storage, subsistence farmers who have limited growing seasons and depend on stored crops are particularly sensitive to extreme rainfall events affecting food quantity and quality ${ }^{27,28}$. Aflatoxin levels in crops increase if storage conditions are not sufficiently dry, while bacterial contamination and foodborne disease are common in the absence of cold storage. Broadly, higher temperatures and changes in rainfall patterns can increase the occurrence of bacteria, viruses, parasites and fungi, and their associated foodborne diseases in stored foods $\mathrm{s}^{25,29,30}$.

Distribution and market access can also be substantially impacted by environmental variability. Floods can disrupt road networks and food trade, typically leading to losses of more perishable or time-sensitive food items $\mathrm{s}^{31,32}$. Compounded by changes in the affordability and diversity of foods available in markets, physical and economic barriers can impact food and nutrition security ${ }^{33}$. Flooding and rising sea levels can also increase water runoff and contamination, leading to increased waterborne disease and chemicals in the food supply ${ }^{25}$. Further, extreme weather events disrupt food distribution by damaging existing infrastructure or slowing food shipments, which can increase risks of food damage, spoilage or contamination ${ }^{34}$. Compared to fresh perishable foods, processed foods may be better able to withstand the impacts of environmental variability related to spoilage, creating a trade-off between the durability, safety and convenience of processed food and their often lower nutritional quality ${ }^{35}$.

Consumption may also be impacted by environmental disruptions through shifts in food availability, affordability and 

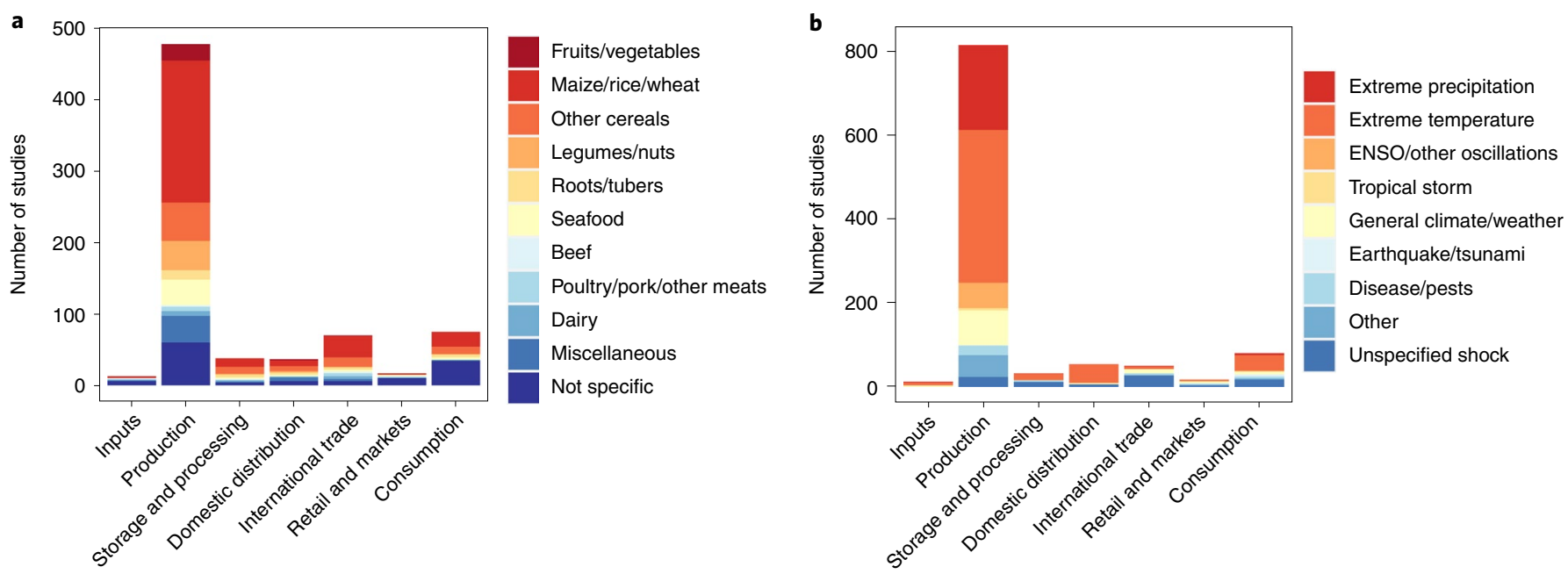

Fig. 2 | Environmental disruptions of food supply chain steps. a,b, Literature review results ( $n=325$ studies) for each supply chain step disaggregated by food group (a) and shock type (b). Studies have concentrated on environmental variability related to the production of maize, wheat and rice and have focused on extreme precipitation and temperature. Certain studies examined more than one food item; as such, the number of observations in the figure exceeds the number of studies.

acceptability. For subsistence farmers, such shifts may directly influence the quantity and quality of foods available for consumption within the household. Reduced incomes and higher food prices can have important implications for nutrition, limiting food purchasing power and leading to shifts in dietary intakes, often towards cheaper highly processed foods ${ }^{36-38}$. Environmental disruptions can also limit the ability to prepare food or to fully absorb nutrients from ingested food, often leading to compromised nutritional outcomes (for example, childhood stunting ${ }^{39}$ ). For instance, in Bangladesh, cooking stoves are often located outside on the ground and can be submerged by flood waters ${ }^{35}$. In Australia, extreme high temperatures were associated with increased risk of intestinal infections and nutritional and metabolic issues among young children ${ }^{40}$. In India, children living in communities exposed to recurring floods were at least 2.3 times more likely to be severely wasted, stunted or underweight $\mathrm{u}^{41,42}$.

Propagation of environmental variability. Understanding the impacts of environmental shocks on food security and nutrition requires connecting production to consumption through all supply chain steps. We analysed peer-reviewed literature to investigate which food items, environmental disruptions and supply chain steps have been the focus of research to date. The scientific evidence for the effects of environmental shocks on food systems is highly concentrated on the main staple crops (maize, rice and wheat) and relatively few types of shock (Figs. 2 and 3). Of the 325 papers examined (Supplementary Table 1), nearly half looked at the impact of shocks on maize, wheat and rice (37\%) and/or other cereals (10\%). Another $18 \%$ did not focus on any specific food item (Fig. 2a). The types of food and shock studied are probably interrelated, as there was an emphasis on the temperature (22\%) and precipitation (41\%) extremes that threaten cereal crops (Fig. 2b). Other shock types, such as cyclones, harmful algal blooms and disease events, were roughly evenly represented in the studies (Fig. 3).

Across the reviewed studies, $42 \%$ focused on a subnational scale (that is, a region within a single country), $35 \%$ on a national scale (that is, a single country) and $15 \%$ on an international scale (that is, multiple countries or global), with the remainder being unspecific about the scale. Of the studies set in a specific country or region, over a quarter were set in Asia and nearly a fifth in Africa. The subnational focus, particularly in regions where subsistence food production makes up a large portion of the food supply, is highly valuable for understanding the impacts of environmental variability on local food security; yet, as a quarter of all food calories are traded internationally ${ }^{43}$, our understanding of the novel food security risks arising from increasingly global food supply chains is limited.

Further, we found that studies on environmental shocks are biased towards production; $89 \%$ included the production stage and $73 \%$ focused on production alone (Fig. 2a). Consumption, here broadly defined as including outcomes related to food expenditure, dietary intake, food security and nutrition outcomes, was included in just $15 \%$ of studies. A similar percentage (16\%) looked at more than one supply chain stage and only $6 \%$ explicitly looked at shock propagation between supply chain steps. Given the heterogeneity of the methods and disciplines that cover the current literature on the propagation of environmental shocks through food supply chains, it was not possible to assess the representativeness or prevalence of specific linkages between environmental variability and food supply chain shock propagation.

In all, our findings indicate that while each step in a food supply chain may be independently affected by environmental variability in various ways (Fig. 1), upstream shocks can be propagated to subsequent supply chain steps under certain conditions-and this variability can be transferred both locally (Box 1) and globally, as exemplified by some studies ${ }^{44-50}$. For more local systems, as in the case of subsistence households, some of these steps are absent or diminished (Box 2), and environmental variability is more likely to affect their diets depending on the availability of substitutes, the effects on household incomes and the quality of the foods consumed. Smallholder farmers who are unable to sell their produce owing to suboptimal quality (or questionable safety) tend to consume it themselves, possibly compromising the nutritional value and diversity of their diets ${ }^{25}$. Low-income populations in urban settings may face a similar trade-off and purchase less expensive foods despite lower quality ${ }^{35,36}$ increasing their exposure to aflatoxin and other foodborne illnesses and disease. For more global food supply chains, a range of recent network-based modelling studies have attempted to evaluate the distant impacts of food supply shocks, finding that highly globalized countries ${ }^{44}$, net importers and low-GDP countries ${ }^{4-47}$, and countries with low strategic reserves ${ }^{48}$ 


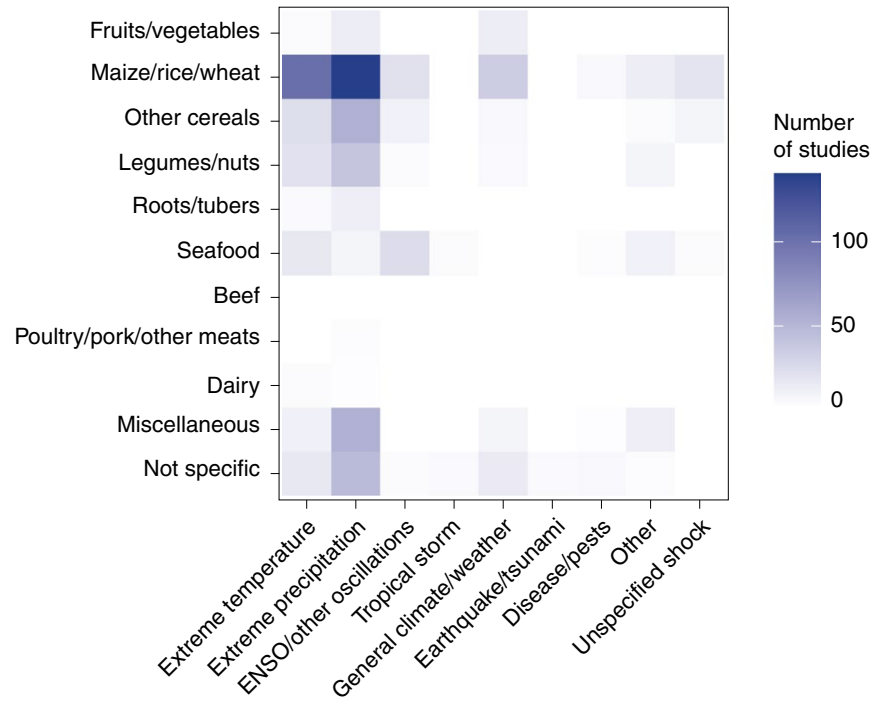

Fig. 3 | Environmental disruptions and food groups. Literature review results disaggregated by shock type and food group ( $n=325$ studies). As a result of the emphasis on staple grain production, studies also heavily focused on related disruptions (that is, extreme temperature and precipitation). Certain studies examined more than one food item; as such, the number of observations in the figure exceeds the number of studies.

are most exposed to external shock events. Other agent-based modelling work has found that shocks travel more easily across networks when the perturbed product is directly traded ${ }^{51}$ and that the indirect economic effects of supply chain shocks (for example, firm-to-firm disruptions that a natural hazard causes) can exceed direct impacts (for example, physical damage from the natural hazard) ${ }^{52}$.

One of the primary ways by which shock propagation along supply chains has been examined in the literature is through the effects of disruptions on prices. Price transmission across supply chains informs economic decisions at various stages, but volatile prices can create uncertainty for downstream supply chain actors ${ }^{53}$. The effect of transmission along a supply chain depends on the structure of the sector and the policy context. Foods with multiple sourcing options, substitute products and longer shelf lives can better buffer supply and dampen variability ${ }^{5,55}$. Concentrated market power also restricts price transmission when retailers exercise their power to keep consumer prices stable during volatile periods ${ }^{53}$. Conversely, foods with few substitutes, foods requiring longer grow-out periods, sectors with fewer industry actors and regions with limited infrastructure tend to have lower capacity to dampen supply or price variability, resulting in greater propagation along the supply chain. In cases where variability reaches consumers (often in the form of price fluctuations), physical and economic access dictates that these shortages are not evenly distributed between countries or between individuals. Thus, it is essential to understand not only how environmental variability can lead to instability in food supply but also how economic mechanisms may be used to modulate these fluctuations across the population.

Supply chain actors and their response option space. Approximately two-thirds of the coping strategies identified through our review focused on the production level. However, there are multiple points across the supply chain where governments, the private sector, intergovernmental, civil society and non-governmental organizations, and individual farmers can act to reduce the negative impact of environmental variability on food security ${ }^{7}$. Indeed, given the interconnectedness of supply chain steps, the full suite of food system actors will need to intervene-from production to consumption - to counteract the many ways in which environmental variability and extreme events manifest and propagate (Fig. 1). Opportunities to address this variability depend on the actor, the step in the supply chain, the timescale of implementation and the type of environmental variability (Table 1 ).

Responses at the production level focused on improving farmers' resilience in terms of producing sufficient quantity and quality of food in the presence of environmental variability. While government institutions (including agricultural ministries, national agricultural research centres, and extension and agricultural policymakers) are the key actors involved in these responses, the private sector, intergovernmental organizations (for example, the World Bank) and other organizations such as CGIAR are also important for enabling stable production ${ }^{56}$. One important way to increase the resilience of agricultural production is by choosing crops, cultivars, species and breeds that are not only less susceptible to stresses such as drought, pests and salinity, but also offer other benefits for livelihoods or nutrition ${ }^{17,57}$. For instance, subsidy programmes in India aimed at promoting traditional climate-resilient cereals can increase iron and zinc supply, lower farmer input requirements and reduce water, energy and emission footprints ${ }^{58}$. The adoption of biofortified crops can potentially offer similar win-win situations; in sub-Saharan Africa, for instance, orange-fleshed sweet potato is more drought tolerant than other staple crops while also improving vitamin $\mathrm{A}$ intake ${ }^{59}$. Overall, programmes to introduce traditional or biofortified foods must consider cultural acceptability and may require promotional efforts to increase the willingness of consumers to shift their tastes to new varieties ${ }^{60,61}$. Other strategies at the production level include: shifting the timing and patterns of planting ${ }^{62}$; adopting agroforestry practices ${ }^{63}$; diversifying farms ${ }^{64}$; increasing the adoption of technology and on-farm infrastructure, agrochemicals and irrigation ${ }^{65}$; water and soil conservation practices ${ }^{66}$; and shifting or expanding growing areas ${ }^{67}$. However, strong extension services are needed to ensure that farmers have the knowledge and skills to change production practices. It is important to note that large multinational companies are often vertically integrated and have increased global connectivity, being more resilient to certain shocks owing to their ability to reallocate production and sourcing in response to climate shocks ${ }^{68,69}$. In other cases, globalized supply chains with specialized foreign markets are at a greater risk to supply chain disruptions ${ }^{70}$.

Investment by governments and other actors, including the private sector, can also increase resilience to environmental variability across supply chains. For example, increasing access to irrigation (where sustainable) ) $^{71,72}$ and promoting water-efficient management practices $^{73}$ can stabilize production during times of drought ${ }^{74}$, while improvements in storage and road infrastructure can help protect harvested crops and ensure market access under extreme weather events $\mathrm{s}^{75}$. Crop and index insurance can protect farmer incomes against environmental risk, particularly in low- and middle-income countries, and in some cases enable them to access credit for investing in inputs, higher-value crop varieties ${ }^{76}$ and new technologies $^{77}$. Besides protecting rural livelihoods, such programmes may be crafted to incentivize more sustainable and resilient on-farm choices.

Food processing strategies can help increase the shelf life of perishable foods (for example, fruits and vegetables), while fortification and product reformulation can increase the nutritional quality of foods-both of which can prevent food insecurity in times of limited food diversity and shortages associated with environmental variability. Given that processed foods may be more resilient to price volatility, ensuring that their consumption does not lead to nutritional compromises is essential. Policy options and outreach efforts at both the retail and consumer level can help incentivize consumption shifts, such as subsidies for more, and taxes for less 


\section{Box 1 | Production impacts of environmental variability and potential effects on food supply}

Food security policies, strategic reserves, trade relations, substitutability and the type of disturbance all determine a government's ability to respond to an environmental disruption. Depending on the ability to enact a timely response, this can ultimately impact food availability to consumers. a, For instance, the December 2004 tsunami in Sri Lanka was associated with a marked decline in seafood production ${ }^{5}$. As much of the country's seafood catch is consumed domestically, this resulted in more than a $20 \%$ decrease in per capita seafood supply relative to the previous year. As a result of shortages in fresh seafood, imports of more expensive dry and canned fish temporarily jumped, with potential knock-on effects for short-term nutrition security in the country. $\mathbf{b}$, Floods in $\mathrm{Pa}-$ kistan in 2010 impacted agriculture with 2.4 million hectares of standing crops, 1 million tonnes of food and seed stocks, and 11 million livestock and poultry either lost or damaged ${ }^{21}$. These impacts on production as well as damage to manufacturing, storage facilities, and rail and road networks led to widespread declines in domestic food grain stocks ( $>60 \%$ of households lost food grain stocks in the short term), and rice imports increased tenfold compared to those in the previous year (although it should be noted that imports constitute only a small fraction of Pakistan's domestic rice supply). c, Droughts in Niger have periodically contributed to substantial declines in livestock production. As nearly all of the meat in Nigerien diets comes from domestic production, these shortfalls have contributed to marked reductions in per capita supply with imports playing no obvious role as a potential buffering strategy. d, In Venezuela, Taura syndrome virus produced strong impacts on shrimp production, with knock-on effects for the country's exports and domestic availability. The shocks shown here were identified in work by the Food and Agriculture Organization of the United Nations ${ }^{21}$, Gephart et al. ${ }^{5}$ and Cottrell et al. ${ }^{8}$. The data came from FAOSTAT ${ }^{122}$.
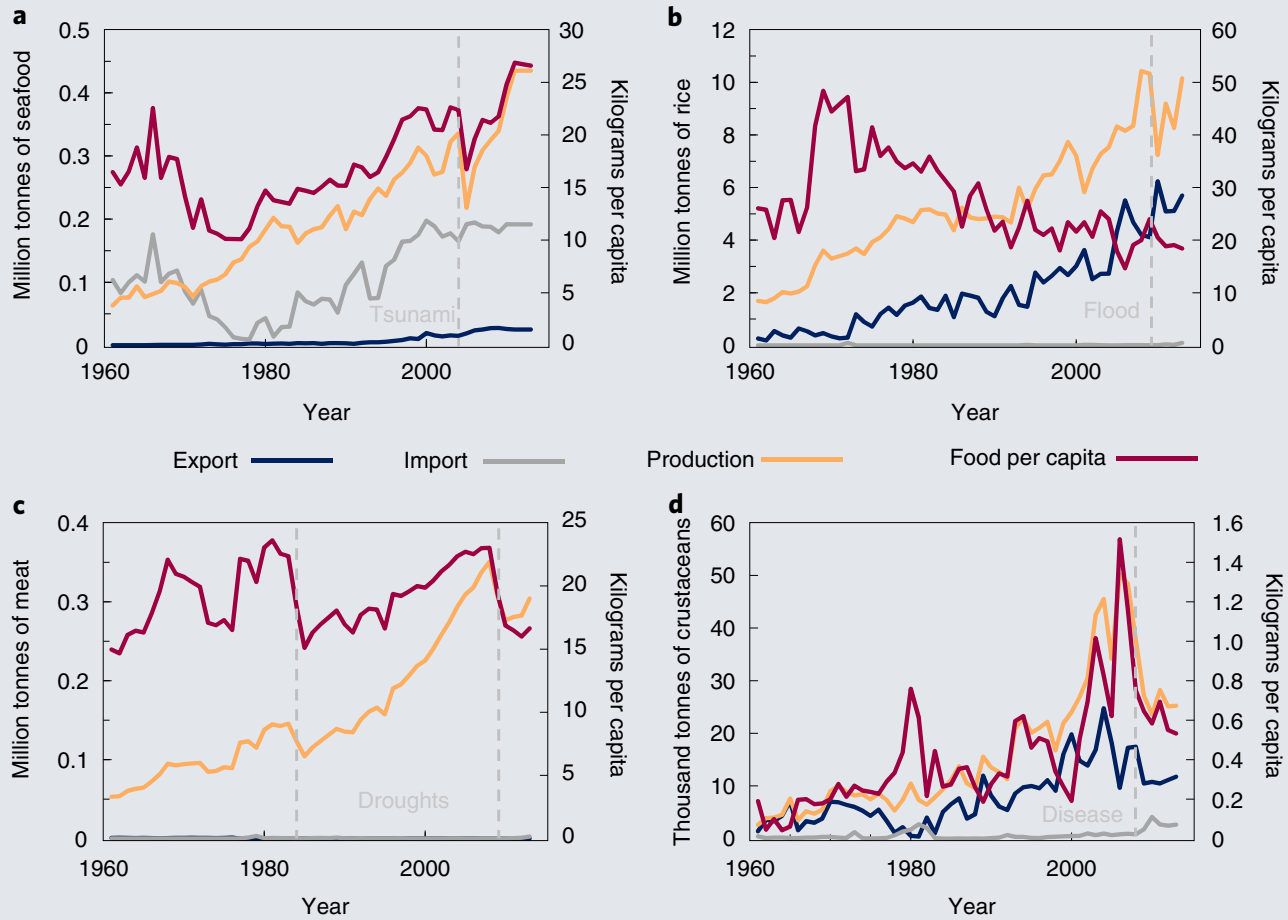

nutritious foods (for example, ultraprocessed foods ${ }^{78-80}$. This is particularly important given that food prices are often the primary driver of food choice and shifts in dietary intake when consumers experience shocks ${ }^{81}$. Social safety nets (for example, provision of cash transfers and food supplementation) can help mitigate the effects of environmental shocks on both food quantity and quality ${ }^{82}$. Also, strengthening food safety standards across supply chains can help ensure greater accountability among actors, including governmental and international bodies such as CODEX Alimentarius (that is, Food Code). Lastly, our review elicited several individual-level responses to environmental variability, such as suspending cultivation, migrating, seeking off-farm employment and selling assets (Table 1).

Increasing cohesion among supply chain actors will be necessary to support responses to growing environmental variability. Actors' different goals can create barriers to such responses, which is especially apparent for trade policy. Given the interconnected- ness of global food systems, a government's policies to support (or thwart) trade can have important implications for their ability-and that of others - to respond to environmental variability ${ }^{83}$. The private sector responds to variability within the constraints of the policy environment set forth by governments, and the extent to which a company is vertically integrated across multiple steps in a food supply chain also determines its suite of options in responding to environmental variability (Box 2). How governments and the World Trade Organization shape trade policies can restrict certain policy responses. For example, shocks are more readily transmitted to importing countries (and disproportionately so to low-income countries ${ }^{47}$ ) owing to an intensification of international trade and changes in the distribution of cereal reserves ${ }^{48}$. Countries at risk of experiencing these shocks can potentially respond by increasing their domestic reserves of cereal commodities or importing from a diverse set of suppliers. For exporting countries, embargoes can help maintain adequate domestic food supplies during times of 


\section{Box 2 | Feedbacks in the food supply chain}

1) Private sector actors exercise substantial influence over the food options available for retail and thereby influence production decisions $^{53}$. These decisions can either enhance or hinder the resilience of production systems to environmental variability. 2) In more globalized food supply chains, the influence of consumer choice and purchasing on production decisions is limited, and there is therefore less individual control over exposure to remote environmental or economic shocks ${ }^{123,124}$. 3) Food corporations are often vertically integrated across multiple steps of the supply chain ${ }^{68,69}$. This can allow a more efficient response to an environmental disturbance (for example, through source switching) but can have serious implications both upstream (for example, promotion of specific varieties/ species) and downstream (for example, fewer dietary options for consumers). 4) Subsistence agriculture directly links production and consumption ${ }^{10}$. On the basis of expected market prices, growing conditions and dietary needs, smallholders can exercise greater control over their production decisions and their exposure to environmental risk, provided that their food basket is nutritionally adequate and that they have sufficient information/forecasting for on-field decisions ${ }^{76,77}$. On one hand, farmers and fishers are afforded flexibility in responding to or anticipating environmental variability. On the other hand, should their adaptive production decisions be imperfect, these households may have fewer alternatives for dietary sourcing compared to more globally connected consumers. 5) Subsistence farmers and fishers are-in general-net purchasers of food and so are still exposed to disruptions in market access and fluctuations in food prices. This can lead to shifts in consumption ${ }^{12}$. 6) Many smallholder farmers and fishers are vertically integrated in that they oversee the production, near-term storage and processing, and transport to local markets ${ }^{10}$. This exposes subsistence agriculture to multiple forms of environmental risk, the interventions to which can be capital intensive and beyond the financial capacity of individual smallholders ${ }^{76}$. This can present challenges in the case of a 'good year' where farmers and fishers have a bumper year ${ }^{114}$. In this case, because storage capabilities are limited, local markets can be flooded with the supply of a particular food item, meaning that smallholders must settle for lower market prices and cannot fully capitalize on this increased production.

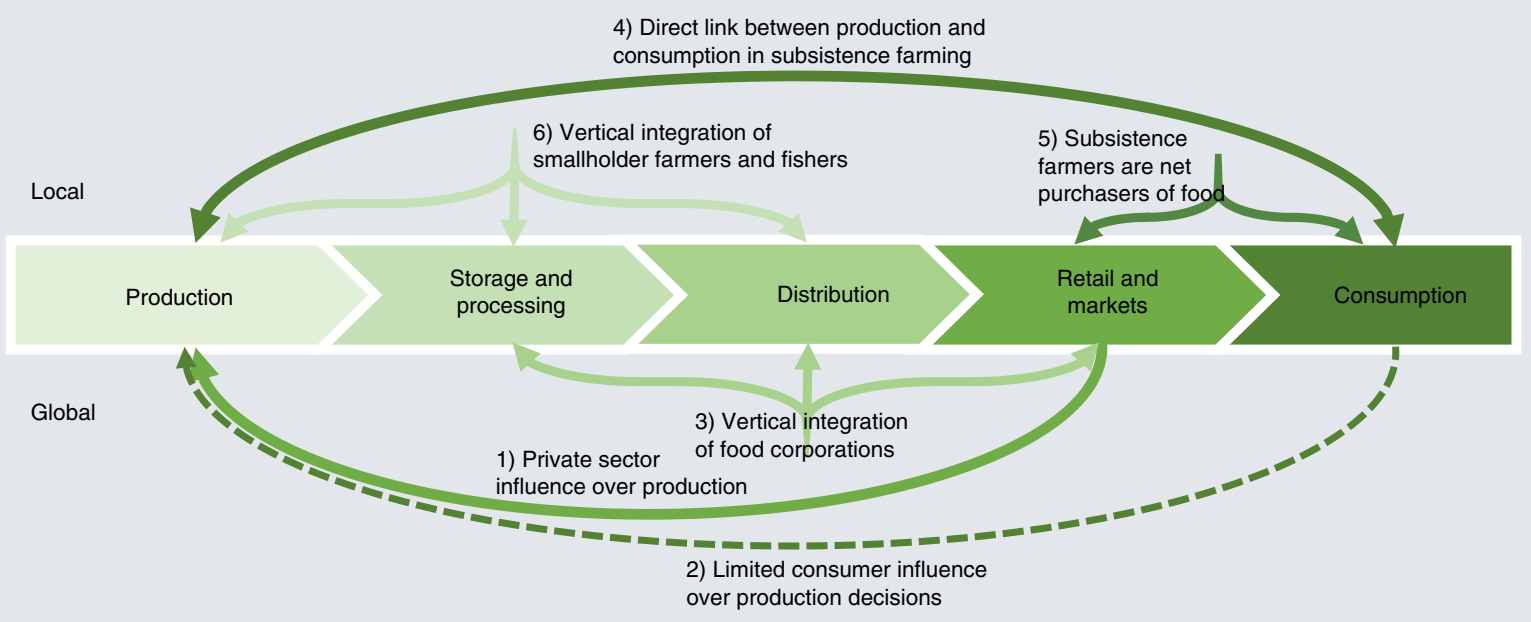

limited production; yet, hoarding and export bans may affect each country's resilience to environmental variability either positively or negatively, depending on the specific actions taken and the commodities targeted $^{13}$. The Bali Package represents one recent effort to address this trade-distorting behaviour by which the World Trade Organization seeks to protect the policy space of governments to quickly enact trade strategies to better ensure domestic food security $^{84}$. It is possible that a similar approach can be taken to allow greater flexibility in responses to environmental variability as well.

Moving beyond food production shocks. Our current understanding of the various ways by which environmental variability affects (and propagates through) food systems is insufficient. Expanding our knowledge beyond a focus on production shocks for staple crops will be essential for enhancing the resilience and sustainability of food supply chains. By considering the various steps and interactions of food supply chains, different actors can more effectively develop targeted interventions to cope with environmental variability and avoid unintended consequences within food systems. In particular, adaptive strategies can be improved by understanding the shape and evolution of food supply chains, the potential for surprises and spillovers, and the risk of simultaneous and unprecedented shocks.
The shape and evolution of food supply chains have gradually evolved away from strong local interactions between producers and consumers towards greater complexity and distance. Over the past half-century, globalization and market consolidation have meant that power over global food system decisions has become concentrated $^{43,85}$. These trends of vertical integration and homogenization have had profound upstream and downstream effects that span supply chains (Box 2)-ranging from ecosystem impacts in areas of production ${ }^{68,86}$ to modified options for consumers ${ }^{87,88}$ while the growing reliance of many countries on food imports has also left them increasingly vulnerable to shocks that occur beyond their borders ${ }^{45,46,89,90}$. The increase in processed or multi-ingredient foods has also led to converging and diverging product streams that make it more difficult to link the sources of raw materials to an end product ${ }^{91}$. Taken together, such changes have also meant that an individual consumer interested in sustainable purchasing is able to exercise less control over the sourcing of their food and the exposure of their diet's production to environmental risk (Box $2)^{85}$. Being able to trace food's passage through a supply chain not only ensures quality and sustainability standards but also allows governments to steer companies towards reliable and less vulnerable food supply decisions beyond economic incentives to do so. Substantial progress has been made to promote traceability in some 


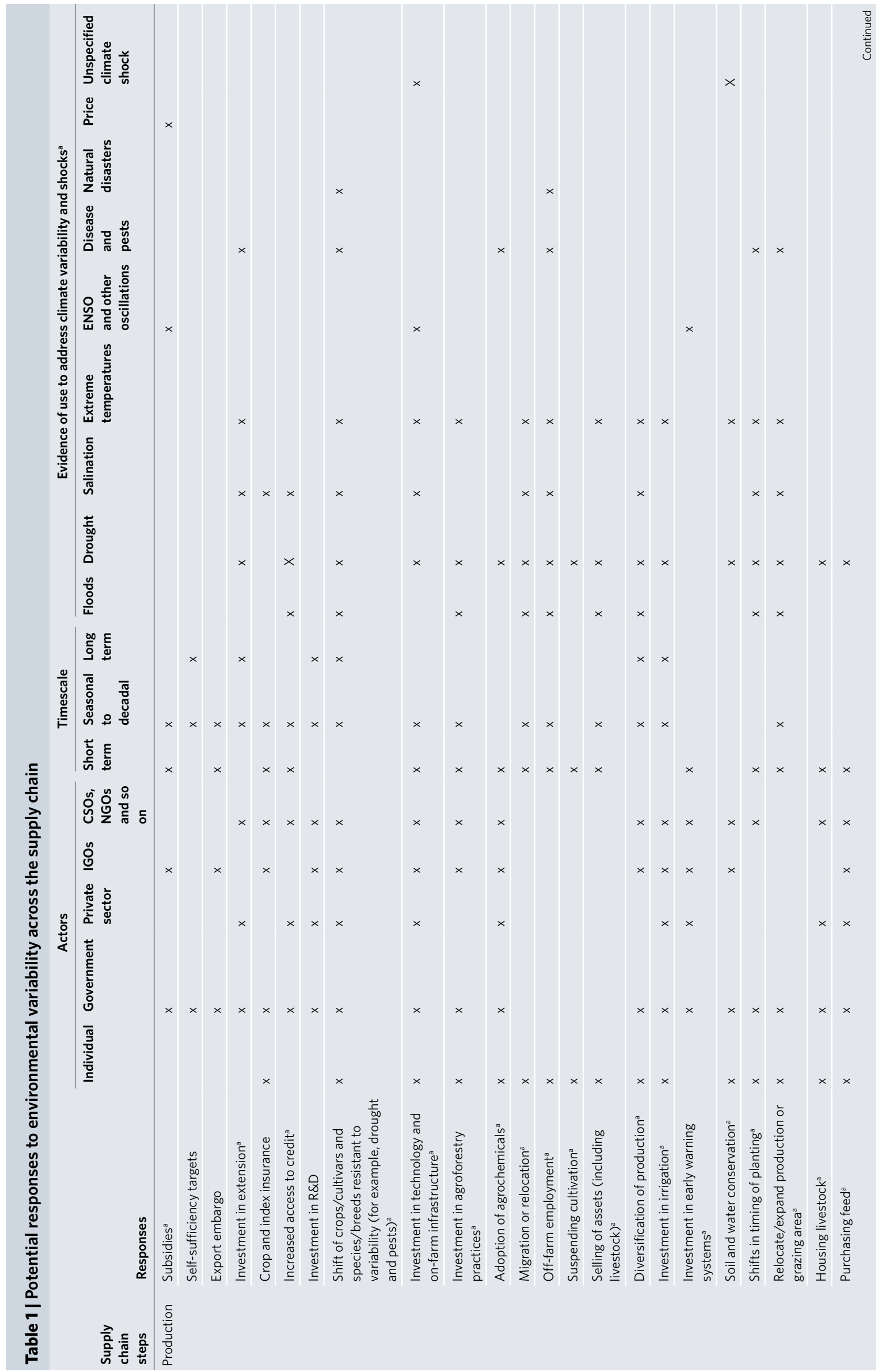




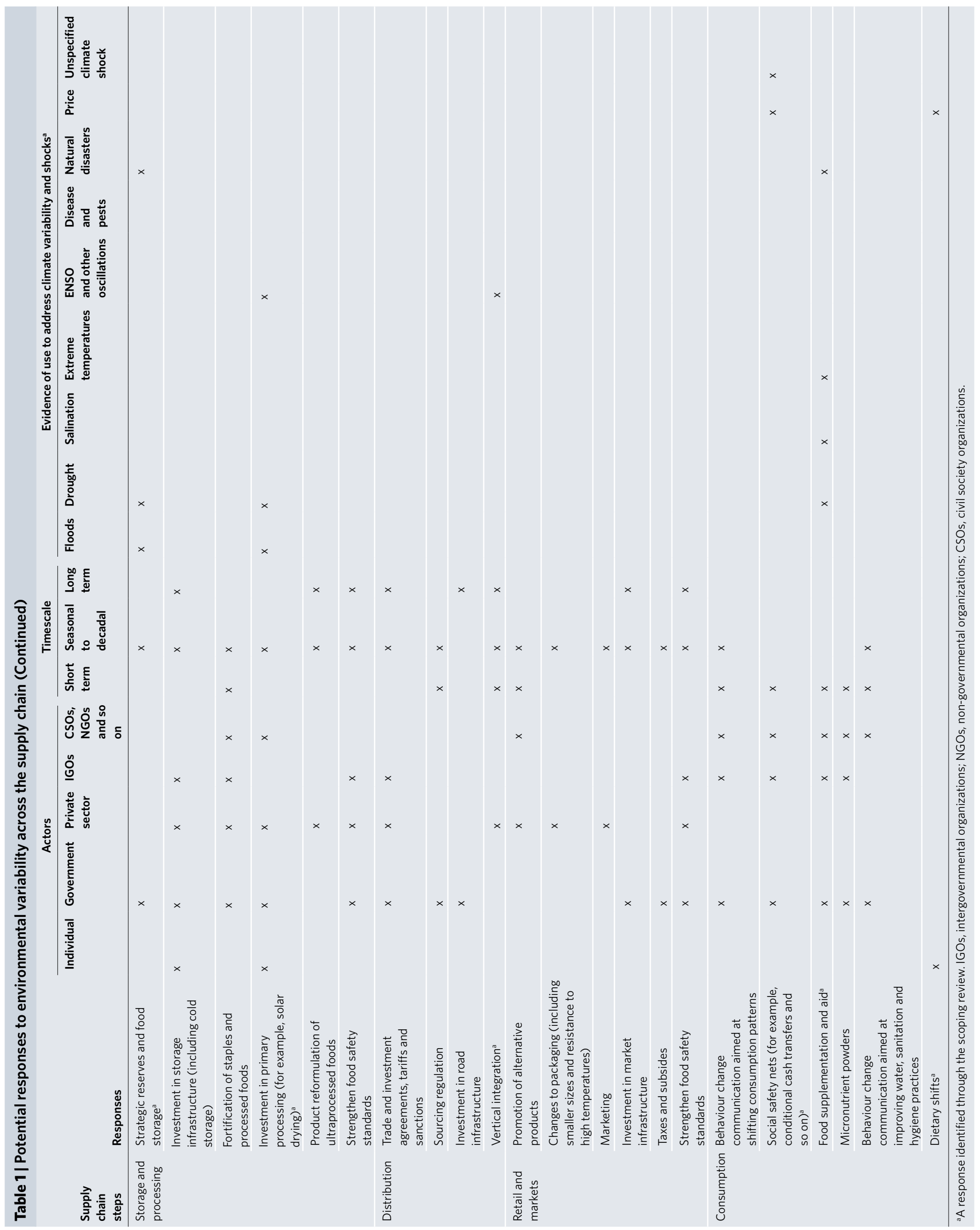


countries (for example, the UK, the Netherlands and Japan) and for selected products (for example, the livestock sector in Uruguay and dairy products in France and the UK); however, for most countries and food items, understanding the steps connecting producers and consumers remains a critical obstacle to enhancing the resilience and adaptability of food supply chains to short-term environmental variability ${ }^{92}$. To address this, a host of innovative approaches offer opportunities to enhance information-sharing capabilities ${ }^{93}$, facilitate real-time responses to supply chain disruptions, couple environmental externalities with production ${ }^{94}$, account for the challenges of monitoring and reporting across countries, and recognize the differences in supply chains between countries and across food items. Key corporate actors that are increasingly influential in the dynamics of food systems ${ }^{95}$ can mobilize independent of governments to address food sustainability and resilience challenges and ultimately benefit from the outcomes ${ }^{96-98}$.

Surprises and spillovers can result from environmental variability due to direct and indirect interactions throughout a supply chain, among different foods and across spatial and temporal scales ${ }^{8}$. Such unexpected events are typical of complex systems, and models fail to capture the range of possible behaviours or the emergent properties of many actors interacting. Actors' behavioural responses may differ within each specific disturbance context, including the prices of substitute foods, the broader economy and responses of other actors ${ }^{99,100}$. Price spikes of an input to food production due to environmental variability can lead actors to substitute resource inputs or consumers to substitute food products, creating spillovers into other supply chains (Fig. 1).

Substitution depends on the availability and affordability of suitable substitutes and can affect production of foods with seemingly little connection. For example, fishmeal and fish oil are important ingredients for some farmed fish and livestock feeds. The vast majority of fishmeal and fish oil is produced along the west coast of South America, and catch is heavily influenced by El Niño conditions, leading to price fluctuations. While alternative feed ingredients are easily available for poultry feeds, there are few nutritionally equivalent alternatives available for some farmed fish, so fluctuations in the fishmeal-oriented fisheries have a greater spillover effect into aquaculture than poultry. While identifying past surprises and spillovers is an important step towards anticipating potential food system responses to environmental variability, such events are difficult to predict. Fostering general resilience through enhancing production and trade diversity, maintaining food reserves and production buffers, managing feedbacks within the food system and supporting leadership and trust at multiple levels ${ }^{101,102}$ offers a path towards maintaining food system function in the face of surprises.

Simultaneous and unprecedented shocks can pose novel risks to global food systems. Agricultural trade agreements have been based on the premise that a disruption in supply can be compensated by increased sourcing from non-impacted areas (and to a limited extent by strategic reserves for certain commodities $\left.{ }^{103,104}\right)$. This paradigm, widely adopted by countries and corporations alike, assumes that shocks in one region occur independent of those in other places and will not be large enough to overwhelm the available pool of food supply and storage ${ }^{48}$. Yet, evidence suggests that large-scale climate teleconnections ${ }^{105-107}$ as well as a changing climate and increasing variability ${ }^{108}$ can lead to simultaneous and/or compounded ${ }^{109,110}$ impacts on crop production. For instance, rising temperatures are expected to increase the likelihood of simultaneous maize production losses in major production areas ${ }^{111}$. Global climate oscillations significantly influence productivity in two-thirds of the world's cropland $^{112}$. Synchronized climate anomalies associated with the trans-Pacific El Niño/Southern Oscillation (ENSO) have led to concurrent influences on major crop yields in geographically distant regions ${ }^{113}$. These studies suggest that maintaining asynchrony and diversity in areas of food production and sourcing-combined with food storage during bumper years-can limit instability in food supplies under increasing climatic and environmental variability ${ }^{114}$. These global teleconnections point to the possibility of coordinated risks that have yet to be adequately incorporated into climate-smart food security strategies. Examining the probability of synchronized extreme climate events and their linkages with agricultural output anomalies can better inform adaptive strategies of food supply chain actors ${ }^{115}$. More broadly, this scoping review points to a lack of investigation of numerous combinations of co-occurring environmental disruptions and the need to understand their effects on (and propagation through) food supply chains.

\section{Conclusions}

Our analysis shows that most research to date has focused on the associations between environmental variability and production. Although there is a growing body of evidence on the associations between environmental variability and nutrition outcomes, little research exists on the exact pathways by which these shocks influence nutrition. In some cases, we know that agriculture can influence nutrition outcomes through food production, income and women's empowerment pathways ${ }^{116}$, but these have not been adequately examined in the context of environmental variability. Moreover, it is unclear the extent to which environmental variability affects nutrition outcomes due to shifts towards poorer-quality diets and/or increased disease risk leading to disruptions in the absorption of nutrients in different contexts. Without this evidence, little can be done to identify the most appropriate responses to environmental variability.

Also, little research has examined the propagation of shocks through food supply chains and their subsequent effect on consumption. This limits our understanding of the true effects of environmental shocks on the food system as a whole and how local shocks can have global impacts (and vice versa). Given the interconnectedness of food systems, a shock that influences one step of the food supply chain will undoubtedly impact subsequent steps. Likewise, a shock in one country or region can have serious implications for another. As our global food systems become more integrated, understanding the dynamics of propagation across supply chains through empirical research is critical to inform adequate interventions.

Our assessment of coping strategies identified a suite of actions that various supply chain actors can adopt in preparation for or in response to environment variability. Our findings indicate that multiple strategies across the food system will be needed in response to environmental variability, but that our ability to identify the most appropriate package of strategies to adopt remains limited. Understanding the specific interventions that can be taken within a variety of contexts to dampen the effects and propagation of environmental variability along food supply chains is critical to link food systems research with actionable outcomes. Moreover, additional research is needed that examines the interaction between people and their food system in response to shocks; these interactions are probably multifaceted and can have important implications for food security, diets and nutritional outcomes.

Finally, increasingly complex and globalized supply chains are exposed to environmental variability and extreme events at multiple points, leading to the possibility of shock propagation, spillovers and simultaneous shock events. The literature on these types of event is relatively scarce, but insights from resilience literature point towards the importance of production and sourcing diversification and strengthening internal feedbacks for enhancing the resilience of the global food production system ${ }^{117}$. Although not an environmental shock, the COVID-19 pandemic has revealed how a shock in one country can have a ripple effect across the globe and how a single event can simultaneously impact multiple geographies and points along the supply chain. Such shocks can produce differential 
effects on food availability (for example, unharvested fields due to reduced on-farm labour), physical (for example, restricted movement and transportation) and economic (for example, loss of livelihoods) access, and intake (for example, dietary shifts towards highly processed foods with an extended shelf life $)^{15,16,118}$. This underscores the urgent need to expand our understanding of shock events beyond their impacts on production, to minimize systemic risks and enhance the capacity to cope with future disruptions.

\section{Methods}

We conducted a systematic scoping review to examine the propagation of environmental shocks throughout food supply chains (Extended data Fig. 1). Scoping reviews apply a systematic approach to reviewing the literature to map the evidence on a given topic and identify the main concepts, theories and knowledge gaps $^{119}$. Given the heterogeneity of the methods and disciplines that cover the literature on the propagation of environmental shocks through food supply chains, a scoping review was chosen as the most appropriate approach to summarize findings from the existing literature ${ }^{119-121}$. We used the PRISMA checklist for scoping reviews to guide our methodological approach (Extended Data Table 1).

The scoping review was conducted in June 2019, with guidance from a medical librarian, using the Web of Science database and the following search terms: environmental variability (or climate variability, shock, propagation, weather, extreme event, disaster); crop (or food, livestock, fish); and production (or nutrition, food security, diet, access, availability, system, supply, trade, price transmission, price volatility). Our inclusion criteria included studies that: were published in English in 2008 or later (to capture articles published after the 2008 global food crisis); examined supply chains in the 1950s or later; measured an outcome that is directly part of the food system (for example, yield, catch, price, production, infrastructure, food quality and safety, and diets (nutrition through the diet pathway)); and focused specifically on an aspect of environmental variability (for example, disasters, temperature/precipitation/humidity extremes, disease or pest outbreaks, algal blooms and ENSO). We also included studies examining price shocks given that many of these shocks are related to environmental variability. We excluded books and book chapters as well as studies that solely assessed climate risks or vulnerability as well as those that examined the impacts of slow-moving climate on food supply chains. To ensure that our search was sufficiently sensitive to identify articles that met our inclusion criteria, we employed an iterative approach to refine the final search strategy. Specifically, we performed a first-iteration identification utilizing a set of initial search terms and examined whether known articles $s^{5,8,11,24,44-49,89,90,105,111}$ that met the inclusion criteria were retrieved. We then repeated the refinement of search terms until the search strategy captured all of the known articles that met our inclusion criteria. The exact search terms were coded in Web of Science as: ("climate

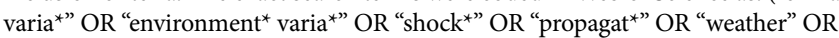
"extreme event" OR "disaster") AND ("crop" ${ }^{\star *}$ " OR "livestock" OR "fish" OR "food*") AND ("production" OR "nutrition*” OR "security" OR "diet*” OR "access" OR "availability” OR "system" OR "supply" OR "trade" OR "price transmission" OR "price volatility") NOT ("food web*”)

The records identified through our search $(n=15,271)$ were imported into $\mathrm{R}$ and any duplicates were removed. All three authors screened the titles and abstracts to assess whether they met our inclusion criteria. Two authors then independently reviewed all abstracts that met our inclusion criteria to verify the screening process. In the event that there was disagreement among the two authors, the third author was consulted and a decision on its inclusion was reached by consensus. We extracted data from articles in two stages: at the abstract and at the full-text review stage. We examined the abstracts that met our inclusion criteria to identify whether the study examined the food supply chain beyond production (that is, yields, productivity and production quality). If the study focused only on production, we extracted data related to the food/crops examined as well as the type of shock. At this stage, we also assessed whether the study solely focused on coping strategies. If the study focused on short-timescale (for example, within a growing season) or intermediate-timescale (for example, switching crops for the following season) coping strategies, we extracted data related to the coping strategies used at this stage as well. The studies that focused solely on coping strategies were then excluded from the full-text review, given that the focus of this paper is on the propagation of shocks across supply chains.

In the second stage of data extraction, we reviewed the full texts of the remaining articles that met our inclusion criteria $(n=325)$. If there was uncertainty regarding whether the study met our inclusion criteria on the basis of the full-text review, the authors jointly discussed the article and came to a consensus on its inclusion. Of the studies that met our inclusion criteria after the full-text review, we extracted information regarding the food/crops examined, the steps of the supply chain considered in the analysis, the type and year of the shock, whether there was propagation and information related to the study methods including the primary outcomes assessed and the study setting. The information extracted from the included studies allowed us to summarize the existing literature and identify gaps in the knowledge base. More specifically, we used the extracted data to quantitatively summarize the types of crop and environmental variability, the supply chain step examined and evidence of propagation along the supply chain. Given the heterogeneity of the included studies, we complemented the quantitative data collection with examples from the included studies to contextualize our findings. All extracted data were recorded into an Excel spreadsheet. We first piloted the data extraction spreadsheet with a small number of articles and made necessary adjustments before completing the data extraction process. Once the extraction was completed, we reviewed the data to ensure that there was consistency in the coding of output variables (for example, crop name and type of environmental variability).

Reporting Summary. Further information on research design is available in the Nature Research Reporting Summary linked to this article.

\section{Data availability}

The data that support the findings of this study are available on GitHub (https:// github.com/jagephart/enviro-shocks-review). The full list of the 325 papers included in this review is provided in Supplementary Table 1.

\section{Code availability}

The code that supports the findings of this study is available on GitHub (https:// github.com/jagephart/enviro-shocks-review).

Received: 22 April 2020; Accepted: 9 November 2020; Published online: 21 December 2020

\section{References}

1. Schmidhuber, J. \& Tubiello, F. N. Global food security under climate change. Proc. Natl Acad. Sci. USA 104, 19703-19708 (2007).

2. Wheeler, T. \& von Braun, J. Climate change impacts on global food security. Science 341, 508-513 (2013).

3. Lesk, C., Rowhani, P. \& Ramankutty, N. Influence of extreme weather disasters on global crop production. Nature 529, 84-87 (2016).

4. Myers, S. S. et al. Climate change and global food systems: potential impacts on food security and undernutrition. Annu. Rev. Public Health 38, 259-277 (2017).

5. Gephart, J. A., Deutsch, L., Pace, M. L., Troell, M. \& Seekell, D. A. Shocks to fish production: identification, trends, and consequences. Glob. Environ. Change 42, 24-32 (2017).

6. Springmann, M. et al. Global and regional health effects of future food production under climate change: a modelling study. Lancet $\mathbf{3 8 7}$, 1937-1946 (2016).

7. Fanzo, J., Davis, C., McLaren, R. \& Choufani, J. The effect of climate change across food systems: implications for nutrition outcomes. Glob. Food Secur. 18, 12-19 (2018).

8. Cottrell, R. S. et al. Food production shocks across land and sea. Nat. Sustain. 2, 130-137 (2019).

9. Rosenzweig, C. et al. Climate change responses benefit from a global food system approach. Nat. Food 1, 94-97 (2020).

10. Vermeulen, S. J. et al. Options for support to agriculture and food security under climate change. Environ. Sci. Policy 15, 136-144 (2012).

11. Badjeck, M.-C., Allison, E. H., Halls, A. S. \& Dulvy, N. K. Impacts of climate variability and change on fishery-based livelihoods. Mar. Policy 34, 375-383 (2010).

12. Dizon, F. \& Herforth, A. The Cost of Nutritious Food in South Asia (World Bank, 2018); http://documents.worldbank.org/curated/ en/382091534429994437/pdf/WPS8557.pdf

13. Headey, D. Rethinking the global food crisis: the role of trade shocks. Food Policy 36, 136-146 (2011).

14. Wellesley, L. How Qatar's food system has adapted to the blockade. Chatham House https://www.chathamhouse.org/expert/comment/ how-qatar-s-food-system-has-adapted-blockade (2019).

15. Reardon, T., Bellemare, M. F. \& Zilberman, D. How COVID-19 may disrupt food supply chains in developing countries. IFPRI Blog https://www.ifpri. org/blog/how-covid-19-may-disrupt-food-sup ply-chains-developing-countries (2020).

16. Challinor, A., Dinesh, D., Läderach, P. \& Van Epp, M. How we can use the COVID-19 disruption to improve food systems and address the climate emergency. CGIAR Blog https://ccafs.cgiar.org/blog/how-we-can-use-covid19-disruption-improve-food-systems-and-address-climate-emergency\#. Xp5iUpl7lPY (2020).

17. Davis, K. F., Rulli, M. C., Seveso, A. \& D’Odorico, P. Increased food production and reduced water use through optimized crop distribution. Nat. Geosci. 10, 919-924 (2017).

18. Samberg, L. H., Gerber, J. S., Ramankutty, N., Herrero, M. \& West, P. C. Subnational distribution of average farm size and smallholder contributions to global food production. Environ. Res. Lett. 11, 124010 (2016).

19. Rosenzweig, C., Iglesias, A., Yang, X. B., Epstein, P. R. \& Chivian, E. Climate change and extreme weather events: implications for food production, plant diseases, and pests. Glob. Change Hum. Health 2, 90-104 (2001). 
20. Fischer, G., Shah, M. \& van Velthuizen, H. Climate Change and Agricultural Vulnerability (IIASA, 2011).

21. The Impact of Disasters on Agriculture and Food Security (FAO, 2015).

22. Porter, J. R. \& Semenov, M. A. Crop responses to climatic variation. Phil. Trans. R. Soc. B 360, 2021-2035 (2005).

23. Hixson, S. M. \& Arts, M. T. Climate warming is predicted to reduce omega-3, long-chain, polyunsaturated fatty acid production in phytoplankton. Glob. Change Biol. 22, 2744-2755 (2016).

24. Hill, D. L. \& Wall, E. Dairy cattle in a temperate climate: the effects of weather on milk yield and composition depend on management. Animal 9, 138-149 (2015).

25. Tirado, M. C., Clarke, R., Jaykus, L. A., McQuatters-Gollop, A. \& Frank, J. M. Climate change and food safety: a review. Food Res. Int. 43, 1745-1765 (2010).

26. How Access to Energy Can Influence Food Losses (FAO, 2016).

27. Vaitla, B., Devereux, S. \& Swan, S. H. Seasonal hunger: a neglected problem with proven solutions. PLoS Med. 6, e1000101 (2009).

28. Chambers, R., Longhurst, R. \& Pacey, A. Seasonal Dimensions to Rural Poverty (Frances Pinter, 1981).

29. Motarjemi, Y., Käferstein, F., Moy, G. \& Quevedo, F. Contaminated weaning food: a major risk factor for diarrhoea and associated malnutrition. Bull. World Health Organ. 71, 79-92 (1993).

30. Käferstein, F. Foodborne diseases in developing countries: aetiology, epidemiology and strategies for prevention. Int. J. Environ. Health Res. 13, S161-S168 (2003).

31. Devereux, S. The impact of droughts and floods on food security and policy options to alleviate negative effects. Agric. Econ. 37, 47-58 (2007).

32. Thornton, P. K., Ericksen, P. J., Herrero, M. \& Challinor, A. J. Climate variability and vulnerability to climate change: a review. Glob. Change Biol. 20, 3313-3328 (2014).

33. Leroy, J. L., Ruel, M., Frongillo, E. A., Harris, J. \& Ballard, T. J. Measuring the food access dimension of food security: a critical review and mapping of indicators. Food Nutr. Bull. 36, 167-195 (2015).

34. Ziska, L. et al. in The Impacts of Climate Change on Human Health in the United States: A Scientific Assessment Ch. 7 (USGCRP, 2016); https://doi. org/10.7930/J0ZP4417

35. Béné, C. et al. Impact of Climate-Related Shocks and Stresses on Nutrition and Food Security in Selected Areas of Rural Bangladesh (World Food Programme, 2015).

36. Scott-Villiers, P., Chisholm, N., Wanjiku Kelbert, A. \& Hossain, N. Precarious Lives: Work, Food and Care after the Global Food Crisis (Institute of Development Studies, 2016)

37. Brinkman, H. J., de Pee, S., Sanogo, I., Subran, L. \& Bloem, M. W. High food prices and the global financial crisis have reduced access to nutritious food and worsened nutritional status and health. J. Nutr. 140, 153S-161S (2009).

38. Martin-Prével, Y. et al. Deterioration in the nutritional status of young children and their mothers in Brazzaville, Congo, following the 1994 devaluation of the CFA franc. Bull. World Health Organ. 78, 108-118 (2000).

39. Phalkey, R. K., Aranda-Jan, C., Marx, S., Höfle, B. \& Sauerborn, R. Systematic review of current efforts to quantify the impacts of climate change on undernutrition. Proc. Natl Acad. Sci. USA 112, E4522-E4529 (2015).

40. Xu, Z. et al. Extreme temperatures and paediatric emergency department admissions. J. Epidemiol. Community Health 68, 304-311 (2014).

41. Rodriguez-Llanes, J. M., Ranjan-Dash, S., Degomme, O., Mukhopadhyay, A. \& Guha-Sapir, D. Child malnutrition and recurrent flooding in rural eastern India: a community-based survey. BMJ Open 1, e000109 (2011)

42. Rodriguez-Llanes, J. M., Ranjan-Dash, S., Mukhopadhyay, A. \& Guha-Sapir, D. Flood-exposure is associated with higher prevalence of child undernutrition in rural eastern India. Int. J. Environ. Res. Public Health 13, 210 (2016)

43. D'Odorico, P., Carr, J. A., Laio, F., Ridolfi, L. \& Vandoni, S. Feeding humanity through global food trade. Earth's Future 2, 458-469 (2014).

44. Tamea, S., Laio, F. \& Ridolfi, L. Global effects of local food-production crises: a virtual water perspective. Sci. Rep. 6, 18803 (2016).

45. Puma, M. J., Bose, S., Chon, S. Y. \& Cook, B. I. Assessing the evolving fragility of the global food system. Environ. Res. Lett. 10, 024007 (2015)

46. Gephart, J. A., Rovenskaya, E., Dieckmann, U., Pace, M. L. \& Brännström $\AA$. Vulnerability to shocks in the global seafood trade network. Environ. Res. Lett. 11, 035008 (2016).

47. Distefano, T., Laio, F., Ridolfi, L. \& Schiavo, S. Shock transmission in the international food trade network. PLoS ONE 13, e0200639 (2018).

48. Marchand, P. et al. Reserves and trade jointly determine exposure to food supply shocks. Environ. Res. Lett. 11, 095009 (2016).

49. Fair, K. R., Bauch, C. T. \& Anand, M. Dynamics of the global wheat trade network and resilience to shocks. Sci. Rep. 7, 7177 (2017)
50. Otto, C., Willner, S. N., Wenz, L., Friler, K. \& Levermann, A. Modeling loss-propagation in the global supply network: the dynamic agent-based model acclimate. J. Econ. Dyn. Control 83, 232-269 (2017).

51. Kuypers, M. A., Beyeler, W. E., Antognoli, M., Mitchell, M. D. \& Glass, R. J. To trade or not to trade: analyzing how perturbations travel in sparsely connected networks. In Proc. Complex Sciences, Complex 2012 (eds Glass, K. et al.) (Springer, 2013).

52. Inoue, H. \& Todo, Y. Firm-level propagation of shocks through supply-chain networks. Nat. Sustain. 2, 841-847 (2019).

53. Assefa, T. T., Meuwissen, M. P. M., Gardebroek, C. \& Oude Lansink, A. G. J. M. Price and volatility transmission and market power in the German fresh pork supply chain. J. Agric. Econ. 68, 861-880 (2017).

54. Lock, K. Potential causes and health effects of rising global food prices. $B$ r. Med. J. 339, b2403 (2009).

55. Price Volatility in Food and Agricultural Markets: Policy Responses (FAO, 2011).

56. Transforming Food and Agriculture to Achieve the SDGs (FAO, 2018).

57. Lin, B. B. Resilience in agriculture through crop diversification: adaptive management for environmental change. BioScience 61, 183-193 (2011).

58. Davis, K. F. et al. Assessing the sustainability of post-Green Revolution cereals in India. Proc. Natl Acad. Sci. USA 116, 25034-25041 (2019).

59. Low, J. W., Mwanga, R. O. M., Andrade, M., Carey, E. \& Ball, A.-M. Tackling vitamin A deficiency with biofortified sweetpotato in sub-Saharan Africa. Glob. Food Secur. 14, 23-30 (2017).

60. Bowser, T. J., Ojwang, F., Sahs, R. \& Brandenberger, L. Promotion of orange flesh sweet potato by demonstration of acceptance and food product development. Afr. J. Food Sci. 11, 383-388 (2017).

61. Hummel, M. et al. Sensory and cultural acceptability tradeoffs with nutritional content of biofortified orange-fleshed sweetpotato varieties among households with children in Malawi. PLoS ONE 13, e0204754 (2018).

62. Butler, E. E., Mueller, N. D. \& Huybers, P. Peculiarly pleasant weather for US maize. Proc. Natl Acad. Sci. USA 115, 11935-11940 (2018).

63. Mbow, C., Smith, P., Skole, D., Duguma, L. \& Bustamante, M. Achieving mitigation and adaptation to climate change through sustainable agroforestry practices in Africa. Curr. Opin. Environ. Sustain. 6, 8-14 (2014).

64. Bowles, T. M. et al. Long-term evidence shows that crop-rotation diversification increases agricultural resilience to adverse growing conditions in North America. One Earth 2, 284-293 (2020).

65. Herrero, M. et al. Innovation can accelerate the transition towards a sustainable food system. Nat. Food 1, 266-272 (2020).

66. Jägermeyr, J. et al. Water savings potentials of irrigation systems: global simulation of processes and linkages. Hydrol. Earth Syst. Sci. 19, 3073-3091 (2015).

67. Sloat, L. L. et al. Climate adaptation by crop migration. Nat. Commun. 11, 1243 (2020).

68. Österblom, H. et al. Transnational corporations as 'keystone actors' in marine ecosystems. PLoS ONE 10, e0127533 (2015).

69. Reardon T. \& Zilberman D. in Climate Smart Agriculture: Natural Resource Management and Policy (eds Lipper, L. et al.) 335-351 (Springer, 2018).

70. Colicchia, C., Dallari, F. \& Melacini, M. Increasing supply chain resilience in a global sourcing context. Prod. Plan. Control 21, 680-694 (2010).

71. Rosa, L. et al. Closing the yield gap while ensuring water sustainability. Environ. Res. Lett. 13, 104002 (2018)

72. Rosa, L., Chiarelli, D. D., Rulli, M. C., Dell'Angelo, J. \& D’Odorico, P. Global agricultural economic water scarcity. Sci. Adv. 6, eaaz6031 (2020).

73. Jägermeyr, J. et al. Integrated crop water management might sustainably halve the global food gap. Environ. Res. Lett. 11, 025002 (2016).

74. Asoka, A., Gleeson, T., Wada, Y. \& Mishra, V. Relative contribution of monsoon precipitation and pumping to changes in groundwater storage in India. Nat. Geosci. 10, 109-117 (2017).

75. De Haen, H. \& Hemrich, G. The economics of natural disasters: implications and challenges for food security. Agric. Econ. 37, 31-45 (2007)

76. Carriquay, M. A. \& Osgood, D. E. Index insurance, probabilistic climate forecasts, and production. J. Risk Insur. 79, 287-300 (2011).

77. Greatrex, H. et al. Scaling Up Index Insurance for Smallholder Farmers: Recent Evidence and Insights (CGIAR, 2015); https://cgspace.cgiar.org/ bitstream/handle/10568/53101/CCAFS_Report14.pdf

78. Andreyeva, T., Long, M. W. \& Brownell, K. D. The impact of food prices on consumption: a systematic review of research on the price elasticity of demand for food. Am. J. Public Health 100, 216-222 (2010).

79. Green, R. et al. The effect of rising food prices on food consumption: systematic review with meta-regression. Br. Med. J. 346, f3703 (2013).

80. Thow, A. M., Downs, S. \& Jan, S. A systematic review of the effectiveness of food taxes and subsidies to improve diets: understanding the recent evidence. Nutr. Rev. 72, 551-565 (2014).

81. D'Souza, A. \& Jolliffe, D. Food insecurity in vulnerable populations: coping with food price shocks in Afghanistan. Am. J. Agric. Econ. 96, 790-812 (2014). 
82. Asfaw, S., Carraro, A., Davis, B., Handa, S. \& Seidenfeld, D. Cash Transfer Programmes for Managing Climate Risk: Evidence from a Randomized Experiment in Zambia (FAO, 2017).

83. Friel, S., Schram, A. \& Townsend, B. The nexus between international trade, food systems, malnutrition and climate change. Nat. Food 1, 51-58 (2020)

84. Thow, A. M., Sharma, S. K. \& Rachmi, C. N. An analysis of Indonesia's shrinking food security policy space under the WTO. Food Secur. 11, 1275-1287 (2019).

85. Gordon, L. J. et al. Rewiring food systems to enhance human health and biosphere stewardship. Environ. Res. Lett. 12, 100201 (2017).

86. Pace, M. L. \& Gephart, J. A. Trade: a driver of present and future ecosystems. Ecosystems 20, 44-53 (2017).

87. Reardon, T. \& Swinnen, J. F. M. Agrifood sector liberalisation and the rise of supermarkets in former state-controlled economies: a comparative overview. Dev. Policy Rev. 22, 515-523 (2004).

88. Hawkes, C. Dietary implications of supermarket development: a global perspective. Dev. Policy Rev. 26, 657-692 (2008).

89. Suweis, S., Carr, J. A., Maritan, A., Rinaldo, A. \& D’Odorico, P. Resilience and reactivity of global food security. Proc. Natl Acad. Sci. USA 112 , 6902-6907 (2015).

90. Bren d'Amour, C., Wenz, L., Kalkuhl, M., Steckel, J. C. \& Creutzig, F. Teleconnected food supply shocks. Environ. Res. Lett. 11, 035007 (2016).

91. Wognum, P. M., Bremmers, H., Trienekens, J. H., van der Vorst, J. G. A. J. \& Bloemhof, J. M. Systems for sustainability and transparency of food supply chains - current status and challenges. Adv. Eng. Inform. 25, 65-76 (2011).

92. Folke, C. et al. Transnational corporations and the challenge of biosphere stewardship. Nat. Ecol. Evol. 3, 1396-1403 (2019).

93. Thienekens, J. H., Wognum, P. M., Beulens, A. J. M. \& van der Vorst, J. G. A. J. Transparency in complex dynamic food supply chains. Adv. Eng. Inform. 26, 55-65 (2012).

94. Balmford, A. et al. The environmental costs and benefits of high-yield farming. Nat. Sustain. 1, 477-485 (2018).

95. Macfadyen, S. et al. The role of food retailers in improving resilience in global food supply. Glob. Food Secur. 7, 1-8 (2015).

96. Howard, P. H. Concentration and Power in the Food System: Who Controls What We Eat? (Bloomsbury Academic, 2009)

97. Cattau, M. E., Marlier, M. E. \& DeFries, R. Effectiveness of Roundtable on Sustainable Palm Oil (RSPO) for reducing fires on oil palm concessions in Indonesia from 2012 to 2015. Environ. Res. Lett. 11, 105007 (2016).

98. Mohan, P. The economic impact of hurricanes on bananas: a case study of Dominica using synthetic control methods. Food Policy 68, 21-30 (2017).

99. Nelson, G. C. et al. Climate change effects on agriculture: economic responses to biophysical shocks. Proc. Natl Acad. Sci. USA 111, 3274-3279 (2014).

100. Macdonald, J. R., Zobel, C. W., Melnyk, S. A. \& Griffis, S. E. Supply chain risk and resilience: theory building through structured experiments and simulation. Int. J. Prod. Res. 56, 4337-4355 (2018).

101. Carpenter, S. R. et al. General resilience to cope with extreme events. Sustainability 4, 3248-3259 (2012).

102. Seekell, D. et al. Resilience in the global food system. Environ. Res. Lett. 12, 025010 (2017).

103. Laio, F., Ridolfi, L. \& D'Odorico, P. The past and future of food stocks. Environ. Res. Lett. 11, 035010 (2016).

104. Schewe, J., Otto, C. \& Frieler, K. The role of storage dynamics in annual wheat prices. Environ. Res. Lett. 12, 054005 (2017).

105. Anderson, W., Seager, R., Baethgen, W. \& Cane, M. Trans-Pacific ENSO teleconnections pose a correlated risk to agriculture. Agric. Forest Meteorol. 262, 298-309 (2018).

106. Hao, Z., Hao, F., Singh, V. P. \& Zhang, X. Quantifying the relationship between compound dry and hot events and El Niño-Southern Oscillation (ENSO) at the global scale. J. Hydrol. 567, 332-338 (2018).

107. Boers, N. et al. Complex networks reveal global pattern of extreme-rainfall teleconnections. Nature 566, 373-377 (2019).

108. Bathiany, S., Dakos, V., Scheffer, M. \& Lenton, T. M. Climate models predict increasing temperature variability in poor countries. Sci. Adv. 4, eaar5809 (2018).
109. Sarhadi, A., Ausín, M. C., Wiper, M. P., Touma, D. \& Diffenbaugh, N. S. Multidimensional risk in a nonstationary climate: joint probability of increasingly severe warm and dry conditions. Sci. Adv. 4, eaau3487 (2018).

110. Zscheischler, J. et al. Future climate risk from compound events. Nat. Clim. Change 8, 469-477 (2018).

111. Tigchelaar, M., Battisti, D. S., Naylor, R. L. \& Ray, D. K. Future warming increases probability of globally synchronized maize production shocks. Proc. Natl Acad. Sci. USA 115, 6644-6649 (2018).

112. Heino, M. et al. Two-thirds of global cropland area impacted by climate oscillations. Nat. Commun. 9, 1257 (2018).

113. Iizumi, T. et al. Impacts of El Niño Southern Oscillation on the global yields of major crops. Nat. Commun. 5, 3712 (2014).

114. Systemic Food Assistance: WFP's Strategy for Leveraging Food Assistance to Improve Food System Performance (WFP, 2018).

115. Janetos, A. et al. The Risks of Multiple Breadbasket Failures in the $21^{\text {st }}$ Century: A Science Research Agenda (Boston Univ., 2017)

116. Herforth, A., Jones, A. \& Pinstrup-Andersen, P. Prioritizing Nutrition in Agriculture and Rural Development: Guiding Principles for Operational Investments (World Bank, 2012).

117. Nyström, M. et al. Anatomy and resilience of the global production ecosystem. Nature 575, 98-108 (2019).

118. Food environments in the COVID-19 pandemic. UNSCN (8 April 2020); https://www.unscn.org/en/news-events/recent-news?idnews $=2040$

119. Tricco, A. C. et al. PRISMA extension for scoping reviews (PRISMA-ScR): checklist and explanation. Ann. Intern. Med. 169, 467-473 (2018).

120. Tricco, A. C. et al. A scoping review on the conduct and reporting of scoping reviews. BMC Med. Res. Methodol. 16, 15 (2016).

121. Sucharew, H. \& Macaluso, M. Methods for research evidence synthesis: the scoping review approach. J. Hosp. Med. 7, 416-418 (2019).

122. FAOSTAT (FAO, 2019); http://www.fao.org/faostat/en/\#data

123. Crona, B. I. et al. Masked, diluted and drowned out: how global seafood trade weakens signals from marine ecosystems. Fish Fish. 17, 1175-1182 (2016).

124. Navarro, C. Spike in lime prices in Mexico linked to disease, unrest in key growing areas. Latin America Data Beat (23 April 2014); https:// digitalrepository.unm.edu/cgi/viewcontent.cgi?article=7066\&context=source mex

\section{Acknowledgements}

We thank W. Baethgen, P. D'Odorico and R. DeFries for their input in improving this work and R. Cottrell for his input on examples of food production shocks. K.F.D. was supported in part by Columbia University's Data Science Institute. J.A.G. was supported by the National Socio-Environmental Synthesis Center under funding received from the National Science Foundation DBI-1052875.

\section{Author contributions}

All authors contributed equally to the study. K.F.D., S.D. and J.A.G. designed and performed the research, analysed the data and wrote the paper.

\section{Competing interests}

The authors declare no competing interests.

\section{Additional information}

Extended data is available for this paper at https://doi.org/10.1038/s43016-020-00196-3. Supplementary information is available for this paper at https://doi.org/10.1038/ s43016-020-00196-3.

Correspondence and requests for materials should be addressed to K.F.D.

Peer review information Nature Food thanks the anonymous reviewers for their contribution to the peer review of this work.

Reprints and permissions information is available at www.nature.com/reprints. Publisher's note Springer Nature remains neutral with regard to jurisdictional claims in published maps and institutional affiliations.

(C) The Author(s), under exclusive licence to Springer Nature Limited 2020 


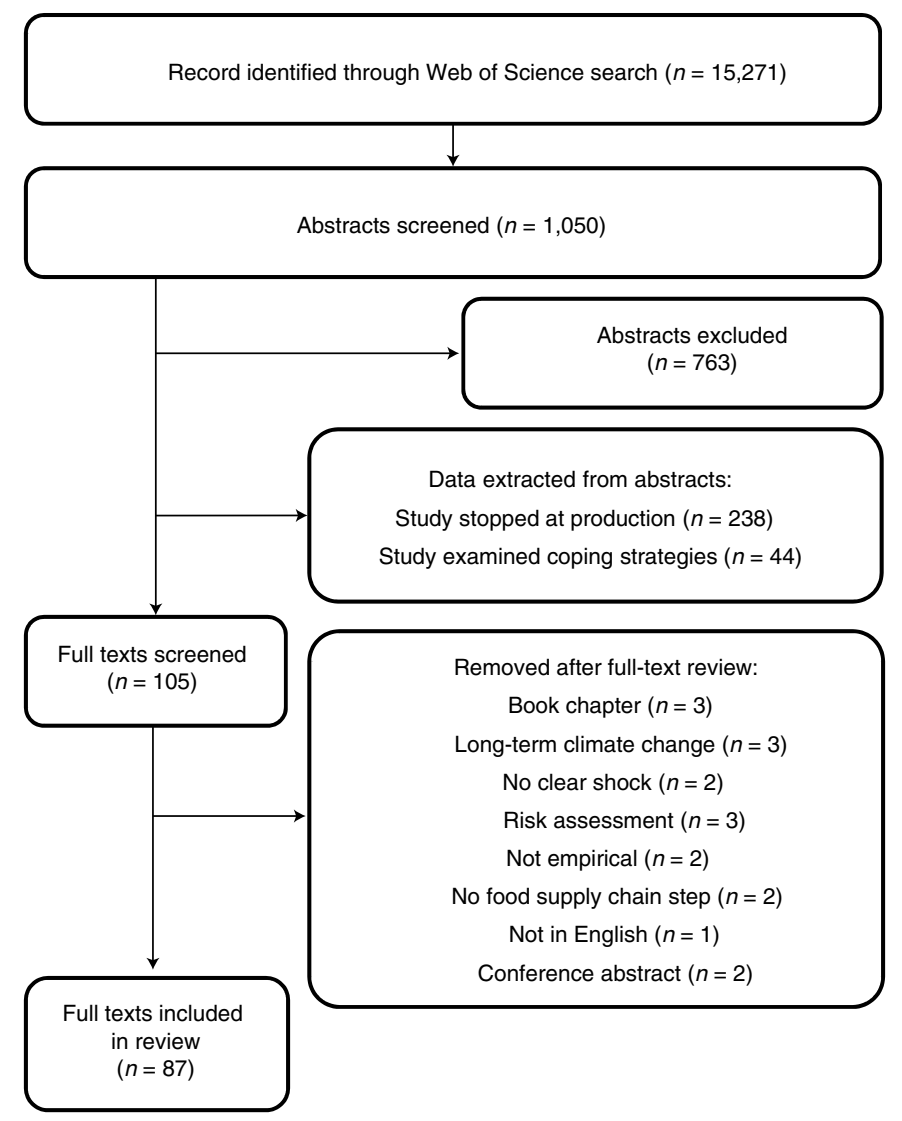

Extended Data Fig. 1 | A diagram of the steps in the scoping review. Each step indicates the number of studies identified in parentheses. 
Extended Data Table 1 | Adherence to PRISMA-ScR scoping review checklist ${ }^{119}$; inclusion of each item within our systematic scoping review is indicated with a Yes $(\mathrm{Y})$, No $(\mathrm{N})$, or Not applicable (N/A)

\begin{tabular}{|c|c|c|}
\hline Section & PRISMA-ScR Checklist item & Included \\
\hline \multicolumn{3}{|l|}{ TITLE } \\
\hline Title & Identify the report as a scoping review. & $\mathrm{N}$ \\
\hline \multicolumn{3}{|l|}{ ABSTRACT } \\
\hline $\begin{array}{r}\text { Structured } \\
\text { summary }\end{array}$ & $\begin{array}{l}\text { Provide a structured summary that includes (as applicable): background, objectives, } \\
\text { eligibility criteria, sources of evidence, charting methods, results, and conclusions that relate } \\
\text { to the review questions and objectives. }\end{array}$ & N/A \\
\hline \multicolumn{3}{|l|}{ INTRODUCTION } \\
\hline Rationale & $\begin{array}{l}\text { Describe the rationale for the review in the context of what is already known. Explain why } \\
\text { the review questions/objectives lend themselves to a scoping review approach. }\end{array}$ & Y \\
\hline Objectives & $\begin{array}{l}\text { Provide an explicit statement of the questions and objectives being addressed with } \\
\text { reference to their key elements (e.g., population or participants, concepts, and context) or } \\
\text { other relevant key elements used to conceptualize the review questions and/or objectives. }\end{array}$ & Y \\
\hline \multicolumn{3}{|l|}{ METHODS } \\
\hline $\begin{array}{l}\text { Protocol and } \\
\text { registration }\end{array}$ & $\begin{array}{l}\text { Indicate whether a review protocol exists; state if and where it can be accessed (e.g., a Web } \\
\text { address); and if available, provide registration information, including the registration } \\
\text { number. }\end{array}$ & $\mathrm{N}$ \\
\hline Eligibility criteria & $\begin{array}{l}\text { Specify characteristics of the sources of evidence used as eligibility criteria (e.g., years } \\
\text { considered, language, and publication status), and provide a rationale. }\end{array}$ & Y \\
\hline $\begin{array}{l}\text { Information } \\
\text { sources* }\end{array}$ & $\begin{array}{l}\text { Describe all information sources in the search (e.g., databases with dates of coverage and } \\
\text { contact with authors to identify additional sources), as well as the date the most recent } \\
\text { search was executed. }\end{array}$ & Y \\
\hline Search & $\begin{array}{l}\text { Present the full electronic search strategy for at least } 1 \text { database, including any limits used, } \\
\text { such that it could be repeated. }\end{array}$ & Y \\
\hline $\begin{array}{r}\text { Selection of sources } \\
\text { of evidencet }\end{array}$ & $\begin{array}{l}\text { State the process for selecting sources of evidence (i.e., screening and eligibility) included in } \\
\text { the scoping review. }\end{array}$ & Y \\
\hline $\begin{array}{r}\text { Data charting } \\
\text { process } \ddagger\end{array}$ & $\begin{array}{l}\text { Describe the methods of charting data from the included sources of evidence (e.g., } \\
\text { calibrated forms or forms that have been tested by the team before their use, and whether } \\
\text { data charting was done independently or in duplicate) and any processes for obtaining and } \\
\text { confirming data from investigators. }\end{array}$ & Y \\
\hline Data items & $\begin{array}{l}\text { List and define all variables for which data were sought and any assumptions and } \\
\text { simplifications made. }\end{array}$ & Y \\
\hline $\begin{array}{r}\text { Critical appraisal of } \\
\text { individual sources } \\
\text { of evidence } \S\end{array}$ & $\begin{array}{l}\text { If done, provide a rationale for conducting a critical appraisal of included sources of } \\
\text { evidence; describe the methods used and how this information was used in any data } \\
\text { synthesis (if appropriate). }\end{array}$ & N/A \\
\hline Synthesis of results & Describe the methods of handling and summarizing the data that were charted. & Y \\
\hline \multicolumn{3}{|l|}{ RESULTS } \\
\hline $\begin{array}{r}\text { Selection of sources } \\
\text { of evidence }\end{array}$ & $\begin{array}{l}\text { Give numbers of sources of evidence screened, assessed for eligibility, and included in the } \\
\text { review, with reasons for exclusions at each stage, ideally using a flow diagram. }\end{array}$ & Y \\
\hline $\begin{array}{l}\text { Characteristics of } \\
\text { sources of evidence }\end{array}$ & $\begin{array}{l}\text { For each source of evidence, present characteristics for which data were charted and } \\
\text { provide the citations. }\end{array}$ & Y \\
\hline $\begin{array}{r}\text { Critical appraisal } \\
\text { within sources of } \\
\text { evidence }\end{array}$ & If done, present data on critical appraisal of included sources of evidence (see item 12). & N/A \\
\hline $\begin{array}{l}\text { Results of individual } \\
\text { sources of evidence }\end{array}$ & $\begin{array}{l}\text { For each included source of evidence, present the relevant data that were charted that } \\
\text { relate to the review questions and objectives. }\end{array}$ & Y \\
\hline Synthesis of results & $\begin{array}{l}\text { Summarize and/or present the charting results as they relate to the review questions and } \\
\text { objectives. }\end{array}$ & Y \\
\hline \multicolumn{3}{|l|}{ DISCUSSION } \\
\hline $\begin{array}{r}\text { Summary of } \\
\text { evidence }\end{array}$ & $\begin{array}{l}\text { Summarize the main results (including an overview of concepts, themes, and types of } \\
\text { evidence available), link to the review questions and objectives, and consider the relevance } \\
\text { to key groups. }\end{array}$ & Y \\
\hline Limitations & Discuss the limitations of the scoping review process. & Y \\
\hline Conclusions & $\begin{array}{l}\text { Provide a general interpretation of the results with respect to the review questions and } \\
\text { objectives, as well as potential implications and/or next steps. }\end{array}$ & Y \\
\hline \multicolumn{3}{|l|}{ FUNDING } \\
\hline Funding & $\begin{array}{l}\text { Describe sources of funding for the included sources of evidence, as well as sources of } \\
\text { funding for the scoping review. Describe the role of the funders of the scoping review. }\end{array}$ & $\mathrm{N} / \mathrm{A}$ \\
\hline
\end{tabular}




\section{natureresearch}

Corresponding author(s): Kyle Frankel Davis

Last updated by author(s): Oct 28, 2019

\section{Reporting Summary}

Nature Research wishes to improve the reproducibility of the work that we publish. This form provides structure for consistency and transparency in reporting. For further information on Nature Research policies, see Authors \& Referees and the Editorial Policy Checklist.

\section{Statistics}

For all statistical analyses, confirm that the following items are present in the figure legend, table legend, main text, or Methods section.

n/a Confirmed

Х $\square$ The exact sample size $(n)$ for each experimental group/condition, given as a discrete number and unit of measurement

Х $\square$ A statement on whether measurements were taken from distinct samples or whether the same sample was measured repeatedly

$\square$ The statistical test(s) used AND whether they are one- or two-sided

$\triangle \square$ Only common tests should be described solely by name; describe more complex techniques in the Methods section.

Х $\square$ A description of all covariates tested

Х $\square$ A description of any assumptions or corrections, such as tests of normality and adjustment for multiple comparisons

X A full description of the statistical parameters including central tendency (e.g. means) or other basic estimates (e.g. regression coefficient)

X $\square$ AND variation (e.g. standard deviation) or associated estimates of uncertainty (e.g. confidence intervals)

$\bigotimes$ For null hypothesis testing, the test statistic (e.g. $F, t, r$ ) with confidence intervals, effect sizes, degrees of freedom and $P$ value noted

$\triangle \square$ Give $P$ values as exact values whenever suitable.

Х $\square$ For Bayesian analysis, information on the choice of priors and Markov chain Monte Carlo settings

Х $\square$ For hierarchical and complex designs, identification of the appropriate level for tests and full reporting of outcomes

Х $\square$ Estimates of effect sizes (e.g. Cohen's $d$, Pearson's $r$ ), indicating how they were calculated

Our web collection on statistics for biologists contains articles on many of the points above.

\section{Software and code}

Policy information about availability of computer code

Data collection N/A

Data analysis The code that supported the findings of this study is available on GitHub (https://github.com/jagephart/enviro-shocks-review).

For manuscripts utilizing custom algorithms or software that are central to the research but not yet described in published literature, software must be made available to editors/reviewers. We strongly encourage code deposition in a community repository (e.g. GitHub). See the Nature Research guidelines for submitting code \& software for further information.

\section{Data}

Policy information about availability of data

All manuscripts must include a data availability statement. This statement should provide the following information, where applicable:

- Accession codes, unique identifiers, or web links for publicly available datasets

- A list of figures that have associated raw data

- A description of any restrictions on data availability

The data that supported the findings of this study are available on GitHub (https://github.com/jagephart/enviro-shocks-review). The full list of 325 papers included this review is included in the Supplementary Information.

\section{Field-specific reporting}

Please select the one below that is the best fit for your research. If you are not sure, read the appropriate sections before making your selection. 


\section{Ecological, evolutionary \& environmental sciences study design}

All studies must disclose on these points even when the disclosure is negative.

Study description
Research sample
Sampling strategy
Data collection
Timing and spatial scale N/A
Reproducibility
Randomization N/A
Blinding N/A
Did the study involve field work? Y Nos

\section{Reporting for specific materials, systems and methods}

We require information from authors about some types of materials, experimental systems and methods used in many studies. Here, indicate whether each material, system or method listed is relevant to your study. If you are not sure if a list item applies to your research, read the appropriate section before selecting a response.

\begin{tabular}{|c|c|}
\hline $\mathrm{n} / \mathrm{a}$ & Involved in the study \\
\hline 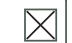 & $\square$ Antibodies \\
\hline 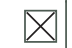 & $\square$ Eukaryotic cell lines \\
\hline$\bigotimes$ & $\square$ Palaeontology \\
\hline$\bigotimes$ & $\square$ Animals and other organisms \\
\hline$\bigotimes$ & $\square$ Human research participants \\
\hline$\bigotimes$ & $\square$ Clinical data \\
\hline
\end{tabular}

Methods

$\mathrm{n} / \mathrm{a}$ Involved in the study

\ $\square$ ChIP-seq

Х $\square$ Flow cytometry

\ $\square$ MRI-based neuroimaging 